\title{
MODIFIED GUIDANCE LAW BASED ON A SLIDING MODE CONTROLLER FOR A MISSILE GUIDANCE SYSTEM
}

\author{
Ali Amer Ahmed Alrawi, Stevica Graovac, R. Badlishah Ahmad, Md. Mijanur Rahman
}

Original scientific paper In this paper, a modified guidance and control sliding mode controller (MGCSMC) method is proposed in a guided missile system. The modified sliding mode controller (MSMC) algorithm is adopted to enable the missile to reach the desired target within a short period of time. The target always makes high manoeuvres when the missile is close to it. This issue has been treated in guidance and control (G\&C) by using a MSMC instead of the traditional method such as proportional navigation method (PN).Theoretical analysis is conducted to reduce the miss-distance and chattering phenomenon in SMC. Simulation of MGCSMC compared with PN method shows an improvement of about $80 \%, 47 \%$ and $20 \%$ for the chattering, miss-distance and finite time, respectively. Furthermore, for the high-altitude target, the MGCSMC improves the acceleration and flight angle of the missile by approximately $65 \%$, and achieves $100 \%$ accuracy, whereas in PN method only $60 \%$ accuracy is achieved under the same conditions.

Keywords: guidance and control systems; missile control; proportional navigation; robustness; sliding mode

Modificirani zakon navođenja utemeljen na regulatoru kliznog režima za sustav vođenja projektila

Izvorni znastveni članak U ovom radu se predlaže metoda modificiranog regulatora navođenja i upravljanja kliznim režimom u sustavu vođenja projektila (MGCSMC). Algoritam modificiranog regulatora kliznog režima (MSMC) koristi se kako bi projektil stigao do željene mete u vrlo kratkom vremenu. Meta uvijek izvodi oštre manevre kad joj se približava projektil. Ovim se pitanjem bavi navođenje i upravljanje (G\&C) primjenjujući algoritam MSMC umjesto tradicionalne metode kao što je proporcionalna metoda navigacije (PN). Provedena je teorijska analiza kako bi se smanjila greška u određivanju udaljenosti i pojava podrhtavanja u SMC. Simulacija MGCSMC u usporedbi s PN metodom pokazuje poboljšanje od oko $80 \%, 47 \%$ i $20 \%$ u odnosu na podrhtavanje, pogrešnu udaljenost i konačno vrijeme. Nadalje, za vrlo visoku metu, MGCSMC poboljšava ubrzanje i nagibni kut putanje leta projektila za približno $65 \%$ te postiže točnost od $100 \%$, dok se PN metodom postiže točnost od samo $60 \%$ pod istim uvjetima.

Ključne riječi: klizni rě̌im; proporcionalna navigacija; robustnost; sustavi navođenja i upravljanja; upravljanje projektilom

\section{Introduction}

A guided missile system performance depends on its G\&C algorithms. Several important functions were performed by using such algorithms. Sensor data used in guidance algorithms are very important in guiding a missile to intercept a target successfully $[1,2]$. G\&C algorithms contribute to lethality by encouraging favourable missile/target geometries [3, 4]. In this paper, G\&C algorithms coordinate the various missile subsystems to ensure that all applicable requirements are met and to consistently maximize the destruction caused by missiles. A missile guidance law takes target data and integrates them with knowledge about the missile state to generate acceleration commands to place the missile

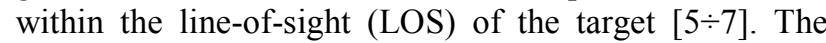
design of such a guidance law plays an important role in determining the final target and departure of the missile. Therefore, the design is a major contributor to the lethality of the overall system. Generally, G\&C algorithms contain adjustable design parameters that control their operation and final performance $[8,9]$. The time constant of the navigation ratio of a proportional navigation (PN) guidance law and the gains of the autopilot are examples of adjustable parameters that are typical first-order performance drivers [10,11]. Almost every part of a G\&C algorithm has an associated adjustable parameter that affects the behaviour of the algorithm and therefore affects the guided missile system.

Once the structure of a G\&C algorithm is established, the design of the algorithm then involves selecting appropriate values for the adjustable parameters.
A suitable value for the algorithm parameters is a difficult matter in a design problem. Analytical techniques, when available, are usually applied within a restricted domain. Often, the designer has a limited understanding of the relative impact of each parameter in a multivariable setting and has a better understanding of single-parameter effects [12]. The sliding mode controller (SMC) law is a substantial case from the large class commonly referred to as the variable structure control. An advantage of these control methods is their robustness to parameter perturbations and bounded external disturbances [13]. The robustness is attributed to the discontinuous term in the control input. However, this discontinuous term also causes an undesirable effect called "chattering". This paper addresses an application of the sliding mode control to design a robust missile command guidance law. The advantage of the modified guidance and control sliding mode controller (MGCSMC) is that its stability can be proved easily in terms of the SMC theory.

This paper is organized as follows. Section 2 discusses the kinematic equations of the missile and target. The nonlinear differential equations that describe missile dynamics are given to show the nonlinearities in the system kinematics and dynamics. Section 3 briefly describes the SMC theory and the derivation of the missile command guidance law. Section 4 presents the investigations of the MGCSMC simulation, which involve designing missile guidance laws based on the MSMC theory. Section 5 provides the results and a discussion of three-dimensional missile-target engagement scenarios. 


\section{Kinematic equations of missile and target}

The three-dimensional command to line-of-sight (CLOS) guidance problem can be formulated as a tracking error problem for a time-varying nonlinear system. The three-dimensional missile-target interception geometry is shown in Fig 1.

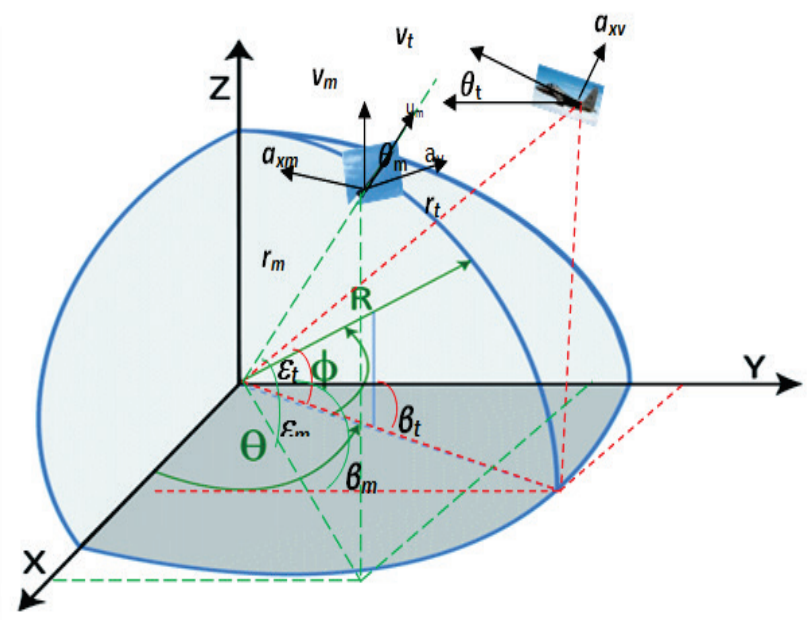

Figure 1 Missile target coordinates

The origin of the inertial frame is located at the ground tracker whereas that of the missile body frame is fixed at the center of gravity of the missile [14].

The representation of the dynamic motion of the missile and the target can be obtained by taking kinematic equations in the geometric space as the azimuth and elevation angles for missile and target $\left(\theta_{m}, \theta_{t}, \varphi_{m}, \varphi_{t}\right)$, side slip angles $\left(\beta_{m}, \beta_{t}\right)$, and error angles $\left(\varepsilon_{m}, \varepsilon_{t}\right)$, which directly affect the composition of the general mathematical formula of equations of motion. The missile acceleration in three-dimensional space is determined as follows:

$\ddot{x}_{m}=a_{x} c\left(\theta_{m}\right) s\left(\varphi_{m}\right)-u_{1}\left(s\left(\beta_{m c}\right) s\left(\theta_{m}\right) c\left(\varphi_{m}\right)+\right.$

$\left.+c\left(\beta_{m}\right) s\left(\varphi_{m}\right)\right)-u_{2}\left(c\left(\varphi_{m c}\right) s\left(\theta_{m}\right) c\left(\varphi_{m}\right)-\right.$

$\left.-s\left(\beta_{m c}\right) s\left(\varphi_{m}\right)\right)$

$\ddot{y}_{m}=a_{x} c\left(\theta_{m}\right) s\left(\varphi_{m}\right)-u_{1}\left(s\left(\beta_{m c}\right) s\left(\theta_{m}\right) c\left(\varphi_{m}\right)-\right.$

$\left.-c\left(\beta_{m}\right) s\left(\varphi_{m}\right)\right)-u_{2}\left(c\left(\varphi_{m c}\right) s\left(\theta_{m}\right) c\left(\varphi_{m}\right)+\right.$ $\ddot{z}_{m}=$

$=a_{x} s\left(\theta_{m}\right)-u_{1}\left(s\left(\beta_{m c}\right) s\left(\theta_{m}\right)\right)+u_{2}\left(c\left(\varphi_{m c}\right) c\left(\theta_{m}\right)\right)-g$.

The missile and target are assumed to be aerodynamically controlled. To confirm this assumption, the missile and target acceleration vectors must be normal to their velocity vectors and depend on the command signals (control force signals: $u_{1}, u_{2}$ ), as expressed in the following equations:

$\dot{\theta}_{m}=u_{1} \frac{s\left(\theta_{m}\right)}{V_{m}}-u_{2} \frac{c\left(\beta_{m}\right)}{V_{m}}-g \frac{c\left(\theta_{m}\right)}{V_{m}}$,

$\dot{v}_{x}=-\frac{u_{1}-u_{2}}{m} s\left(\theta_{m}\right)$

$\dot{v}_{y}=\frac{u_{1}-u_{2}}{m} c\left(\theta_{m}\right)$.

A rotational motion of the missile in the pitch plane (Fig. 1) is described as follows:

$\left\{\begin{array}{l}\dot{\theta}=q \\ \ddot{\theta}=-\frac{l u_{1}}{J}\end{array}\right.$

where $q$ is the pitch rate (red/s), $J$ is the moment of inertia $\left(\mathrm{kg} \cdot \mathrm{m}^{2}\right), l$ is the distance between control forces $u_{1}$, and $C G_{m}$ (is the missile centre of gravity).

The missile velocity is given by

$v_{m}=\sqrt{\dot{x}_{m}^{2}+\dot{y}_{m}^{2}+\dot{z}_{m}^{2}}$,

$u_{1}$ and $u_{2}$ represent the pitch and yaw command of the missile, respectively, while $a_{x}$ represents the axial acceleration of the missile given by

$a_{x}=\frac{T-D}{m}$,

where is $T$ is the thrust, $D$ is the drag, and $m$ is the mass of the missile. The transformation matrix of acceleration in three axes can be represented as Eq. (10).

$\left[\begin{array}{l}\ddot{x}_{m} \\ \ddot{y}_{m} \\ \ddot{z}_{m}\end{array}\right]=\ldots\left[\begin{array}{ccc}c\left(\theta_{m}\right) c\left(\varphi_{m}\right) & s\left(\varphi_{m c}\right) s\left(\theta_{m}\right) c\left(\varphi_{m}\right)+c\left(\beta_{m c}\right) s\left(\varphi_{m}\right) & c\left(\varphi_{m c}\right) s\left(\theta_{m}\right) c\left(\varphi_{m}\right)-c\left(\beta_{m c}\right) s\left(\varphi_{m}\right) \\ c\left(\theta_{m}\right) s\left(\varphi_{m}\right) & s\left(\varphi_{m c}\right) s\left(\theta_{m}\right) s\left(\varphi_{m}\right)-c\left(\beta_{m c}\right) s\left(\varphi_{m}\right) & c\left(\varphi_{m c}\right) s\left(\theta_{m}\right) c\left(\varphi_{m}\right)-s\left(\beta_{m c}\right) c\left(\varphi_{m}\right) \\ s\left(\varphi_{m}\right) & s\left(\theta_{m}\right) c\left(\varphi_{m}\right) & c\left(\varphi_{m c}\right) c\left(\theta_{m}\right)\end{array}\right] \ldots\left[\begin{array}{c}a_{x} \\ a_{y c} \\ a_{z c}\end{array}\right]-\left[\begin{array}{c}0 \\ 0 \\ g\end{array}\right]$.

A practical tracking error choice in the CLOS guidance missile is given by

$\left[\begin{array}{l}e_{1} \\ e_{2}\end{array}\right] \cong\left[\begin{array}{c}\Delta \beta \\ \Delta \varepsilon\end{array}\right] \cong\left[\begin{array}{c}\beta_{m}-\beta_{t} \\ \varepsilon_{m}-\varepsilon_{t}\end{array}\right]$

Another approach for the tracking error choice can be represented as $\left[\begin{array}{l}e_{1} \\ e_{2}\end{array}\right] \cong\left[\begin{array}{cc}\sqrt{x_{m}^{2}+y_{m}^{2}} & 0 \\ 0 & r_{m}\end{array}\right]\left[\begin{array}{c}\beta_{m}-\beta_{t} \\ \varepsilon_{m}-\varepsilon_{t}\end{array}\right]$

A large missile distance from the above equation may occur if the missile flies farther from the launching point. To overcome this problem, a third tracking error choice could be represented as follows: 


$$
\left[\begin{array}{l}
e_{1} \\
e_{2}
\end{array}\right] \cong\left[\begin{array}{ccc}
-s\left(\beta_{t}\right) & c\left(\beta_{t}\right) & 0 \\
-s\left(\varepsilon_{t}\right) c\left(\beta_{t}\right) & -s\left(\varepsilon_{t}\right) s\left(\beta_{t}\right) & -c\left(\varepsilon_{t}\right)
\end{array}\right]\left[\begin{array}{l}
x_{m} \\
y_{m} \\
z_{m}
\end{array}\right]
$$

Eq. (13) indicates the accuracy for a high-altitude target.

\section{Sliding mode design}

Dynamic guidance and control algorithms can be developed for the sliding mode technique $[15,16]$. The effortlessness of the SMC design is due to the fact that investigations of the target parameters are not required. Only $\varepsilon, \beta$ and $\dot{\varepsilon}$ and $\dot{\beta}$ must be measured or estimated for the interceptor. The sliding mode controller is used to achieve two goals: first, to direct the velocity vector of the interceptor, $V_{m}$, to the target by following the line-of-sight angle $\varepsilon$ to the interceptor flight path angle $\beta$ regardless of disturbances and uncertainties [17]; second, to reduce chattering on the flight path angle $\beta$. We evaluated the SMC designs for a surface-to-air missile (SAM) [18]. To achieve the first goal for the SMC, the following tracking motion is given:
To address the attitude control problem, the SMC is designed to have a robust preferred tracking motion

$$
\lim _{t \rightarrow \infty}\left|\varepsilon_{t}-\theta_{m}\right|=0
$$

Eq. (15) indicates that the rotational motion is not affected by the deflection control force, $u_{d}$. Therefore, the second goal will be addressed based on the first goal via the design of an attitude SMC $u_{1}$. The first aim, Eq. (14), will be achieved through the design of a deflection command on SMC $u_{2}$. To address the attitude control problem, Eq. (15), a sliding surface was designed $[19 \div 21]$.

$\sigma_{2}=\dot{e}_{2}+c_{2} e_{2}=0$

From Eq. (13)

$$
\begin{aligned}
& e_{1}=-\sin \left(\beta_{t}\right) x_{m}+\cos \left(\beta_{t}\right) y_{m}, \\
& e_{2}=-\sin \left(\varepsilon_{t}\right) \cos \left(\beta_{t}\right) x_{m}-\sin \left(\varepsilon_{t}\right) \sin \left(\beta_{t}\right) y_{m}-\cos \left(\varepsilon_{t}\right) z_{m},
\end{aligned}
$$

then the derivatives of $e_{2}$ are $\lim _{t \rightarrow \infty}\left|\varepsilon_{t}-\varepsilon_{m}\right|=0$

$\dot{e}_{2}=\frac{x_{m} \sin \left(\beta_{t}-\varepsilon_{m}\right)-y_{m} \cos \left(\beta_{t}-\varepsilon_{m}\right)-y_{m} \cos \left(\beta_{t}+\varepsilon_{m}\right)+x_{m} \sin \left(\beta_{t}+\varepsilon_{m}\right)}{2}$.

The small $\beta_{t}$ is substituted in Eq. (17)

$\dot{e}_{2}=-x_{m} \cos \left(\varepsilon_{m}\right)$,

$\dot{\sigma}_{2}=\Delta \ddot{\varepsilon}_{m, t}+c_{2} \dot{e}_{2}$

Substituting Eq. (18) to (19) results in

$\dot{\sigma}_{2}=\ddot{\varepsilon}_{t}-\ddot{\varepsilon}_{m}-c_{2} x_{m} \cos \left(\varepsilon_{m}\right)$.

If $\varepsilon \cong \theta$, then Eq. (20) will be

$$
\begin{aligned}
& \dot{\sigma}_{2}=\dot{\theta}_{t}-\dot{\theta}_{m}-c_{2} x_{m} \cos \left(\theta_{m}\right), \\
& \dot{\sigma}_{2}=\dot{\theta}_{t}-\dot{\theta}_{m}-c_{2} \frac{-l x_{m} u_{1}}{J} .
\end{aligned}
$$

A contender to the Lyapunov's function is

$$
L_{p}=\frac{\sigma_{2}^{2}}{2}>0,
$$

and its derivative is identified as

$$
\dot{L}_{p}=\sigma_{2} \dot{\sigma}_{2}=\sigma_{2}\left(\ddot{\theta}-c_{2} \frac{-l x_{m} u_{1}}{J}\right) \text {. }
$$

As long as a finite-time meeting to $\sigma_{2}=0$, the control law $u_{1}$ is designed to meet the following inequality [22]: $\sigma_{2} \dot{\sigma}_{2}<\epsilon$

$u_{e q}=\frac{J}{l}\left(\ddot{\theta}+c_{2} \dot{x}_{m} \sin \left(\varepsilon_{m}\right)\right)$.

For small $\varepsilon_{m} \sin \left(\varepsilon_{m}\right)=\varepsilon_{m}$, Eq. (26) becomes

$u_{e q}=\frac{J}{l}\left(\ddot{\theta}+c_{2} \dot{x}_{m} \varepsilon_{m}\right)$

The new method of designing the MSMC depends on the state feedback controller. The control equation contains two parts, namely, the continuous controller equivalent controller $\left(u_{e q}\right)$ and the sliding mode controller, which discontinues the controller. The gain of the sliding mode controller depends on the state feedback theory. Therefore, the first traditional formula can be written as

$u_{1}=u_{e q}-\operatorname{Ksign}\left(\sigma_{2}\right)$

The state space can explain the full state feedback of the missile as

$\left[\begin{array}{c}\dot{x}_{1} \\ \dot{x}_{2}\end{array}\right]=\left[\begin{array}{cc}0 & 1 \\ -a_{1} & -a_{2}\end{array}\right]\left[\begin{array}{l}x_{1} \\ x_{2}\end{array}\right]+\left[\begin{array}{c}0 \\ b_{2}\end{array}\right] u$,

$u(t)=-K x(t)$ 
where $x_{1}$ and $x_{2}$ represent the position and velocity of the missile respectively and $K$ is a state feedback gain that can be evaluated by using Eq. (30)

$$
K=\left[\begin{array}{ll}
k_{1} & k_{2}
\end{array}\right],(31)
$$

where $k_{1}$ and $k_{2}$ can be computed by pole placement method. Combining the sliding mode criteria with state feedback gain will reformulate Eq. (30) as

$u(t)=-K x(t) \times \operatorname{sign}(\sigma)$.

Substituting Eq. (31) in Eq. (32)

$u(t)=\left[-k_{1} \operatorname{sign}(\sigma)-k_{2} \operatorname{sign}(\sigma)\right] x(t)$.

The known state feedback formula is

$\dot{x}(t)=A x(t)-B K x(t)$.

Combining the sliding controller with state space feedback results in

$\dot{x}(t)=A x(t)-B K x(t) \times M \operatorname{sign}(\sigma)$,

where $M= \begin{cases}\alpha & \text { if } \sigma_{x}>0 \\ \beta & \text { if } \sigma_{x}<0\end{cases}$

$\dot{x}(t)=((A-B K M \operatorname{sign}(\sigma)) x(t))$.

Substituting (33) in (34) results in

$$
\begin{aligned}
& {\left[\begin{array}{l}
\dot{x}_{1} \\
\dot{x}_{2}
\end{array}\right]=}
\end{aligned}
$$

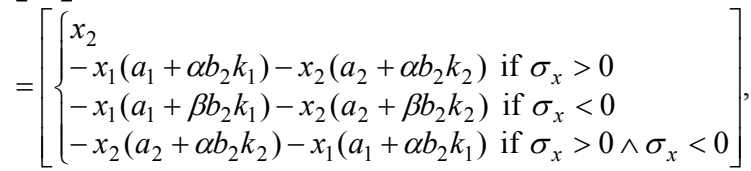

where $\sigma_{x}=x_{1}\left(c_{1} x_{1}+x_{1}\right)$.

Eq. (35) can be rewritten as

$$
\begin{aligned}
& \dot{x}_{1}=x_{2} \\
& \dot{x}_{2}=-x_{1}\left(a_{1}+\alpha b_{2} k_{1} \operatorname{sign}(\sigma)\right)-x_{2}\left(a_{2}+\alpha b_{2} k_{2} \operatorname{sign}(\sigma)\right) .
\end{aligned}
$$

In Eq. (36), the terms $\left(k_{1}, k_{2}\right)$ are very crucial. In a case with a large and fixed $K$, the chattering increases as the adjustable gain of state feedback is proportional with missile target states. The decrease of the gain parameter to an appropriate value ensures that the mounted missile trajectory is close to the LOS and reduces the chattering which results from a conventional sliding mode controller.

\section{Simulation scenarios}

In this section, the MGCSMC algorithm was adopted and included Eq. (14) to (36). The simulation was conducted by using three degrees of freedom. Fig. 2 illustrates the MGCSMC flowchart.

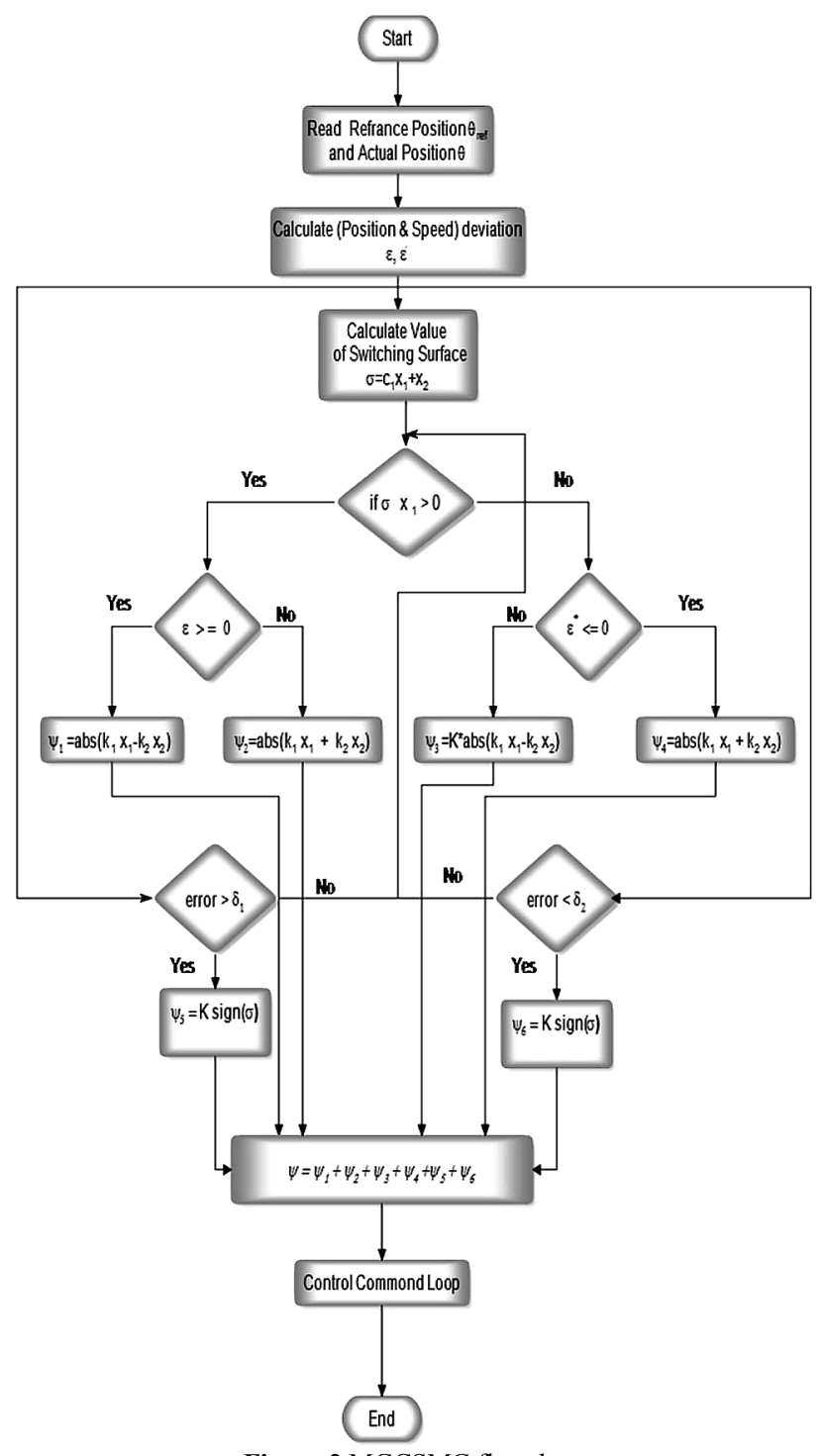

Figure 2 MGCSMC flowchart

\begin{tabular}{|c|c|c|c|c|c|c|}
\hline Parameters & $\begin{array}{c}\text { Mass } \\
\mathrm{kg}\end{array}$ & $\begin{array}{c}\text { Moment } \\
\text { of inertia } \\
\mathrm{kg} \cdot \mathrm{m}^{2}\end{array}$ & $\begin{array}{c}\text { Initial } \\
\text { position } \\
\text { in } x \text {-axis } \\
\text { m }\end{array}$ & $\begin{array}{c}\text { Initial } \\
\text { position } \\
\text { in } y \text {-axis } \\
\mathrm{m}\end{array}$ & $\begin{array}{c}\text { Velocity } \\
\mathrm{m} / \mathrm{s}\end{array}$ & $\begin{array}{c}\text { Pitch } \\
\text { angle } \\
\text { red. }\end{array}$ \\
\hline Missile & 380 & 120 & 0 & 0 & 320 & 0.959 \\
\hline Target & 600 & 60 & 18000 & 15000 & 180 & 0.2 \\
\hline
\end{tabular}

Table 1 Missile and target parameters

\begin{tabular}{|l|c|c|c|c|c|c|}
\hline Parameters & $\begin{array}{c}\text { Mass } \\
\mathrm{kg}\end{array}$ & $\begin{array}{c}\text { Moment } \\
\text { of inertia } \\
\mathrm{kg} \cdot \mathrm{m}^{2}\end{array}$ & $\begin{array}{c}\text { Initial } \\
\text { position } \\
\text { in } x \text {-axis } \\
\mathrm{m}\end{array}$ & $\begin{array}{c}\text { Initial } \\
\text { position } \\
\text { in } y \text {-axis } \\
\mathrm{m}\end{array}$ & $\begin{array}{c}\text { Velocity } \\
\mathrm{m} / \mathrm{s}\end{array}$ & $\begin{array}{c}\text { Pitch } \\
\text { angle } \\
\text { red. }\end{array}$ \\
\hline Missile & 380 & 120 & 0 & 0 & 320 & 0.9 \\
\hline Target & 600 & 60 & 5000 & 12000 & 180 & 0.2 \\
\hline
\end{tabular}

Table 2 Missile and target parameters

The simulation results confirm the effectiveness of the proposed sliding mode controller. The simulation involves two scenarios. In the first scenario, which involves a low altitude, the target was incoming to the missile station $(0,0)$ while performing a variety of maneuvers, e.g., $-25^{\circ},-30^{\circ}, 35^{\circ}$, and $55^{\circ}$. The initial conditions of the missile and the target in this scenario are summarized in Tab. 1. In the second scenario, which 
involves a high altitude, the target departed from the missile station while performing the same manoeuvres, e.g., $-25^{\circ},-30^{\circ}, 35^{\circ}$, and $55^{\circ}$. The initial conditions of the missile and the target in this scenario are summarized in Tab. 2. The simulation includes flexible effects. For purposes of simplicity, however, these flexible effects were neglected in the analysis. The simulation assumed that from zero to four seconds, the missile will be in an open loop (no command received from control unit), and after four seconds, the actuator of the missile will begin to receive command data from the MGCSMC unit.

\section{Flowchart and schematic of the MGCSMC}

Fig. 2 and 3 present the overall simulation, flowchart, and schematic diagram which represent the missile, target, and guidance control unit, respectively. The simulation represented all mathematical equations of the motion and missile target trigonometry indicated from Eqs. (1) to (13). The simulation includes

1. Attitude unit to determine the missile and target attitude

2. Model of missile and target

3. G\&C system unit

4. Radar simulation to find LOS angle unit

5. Miss distance and fuse unit.

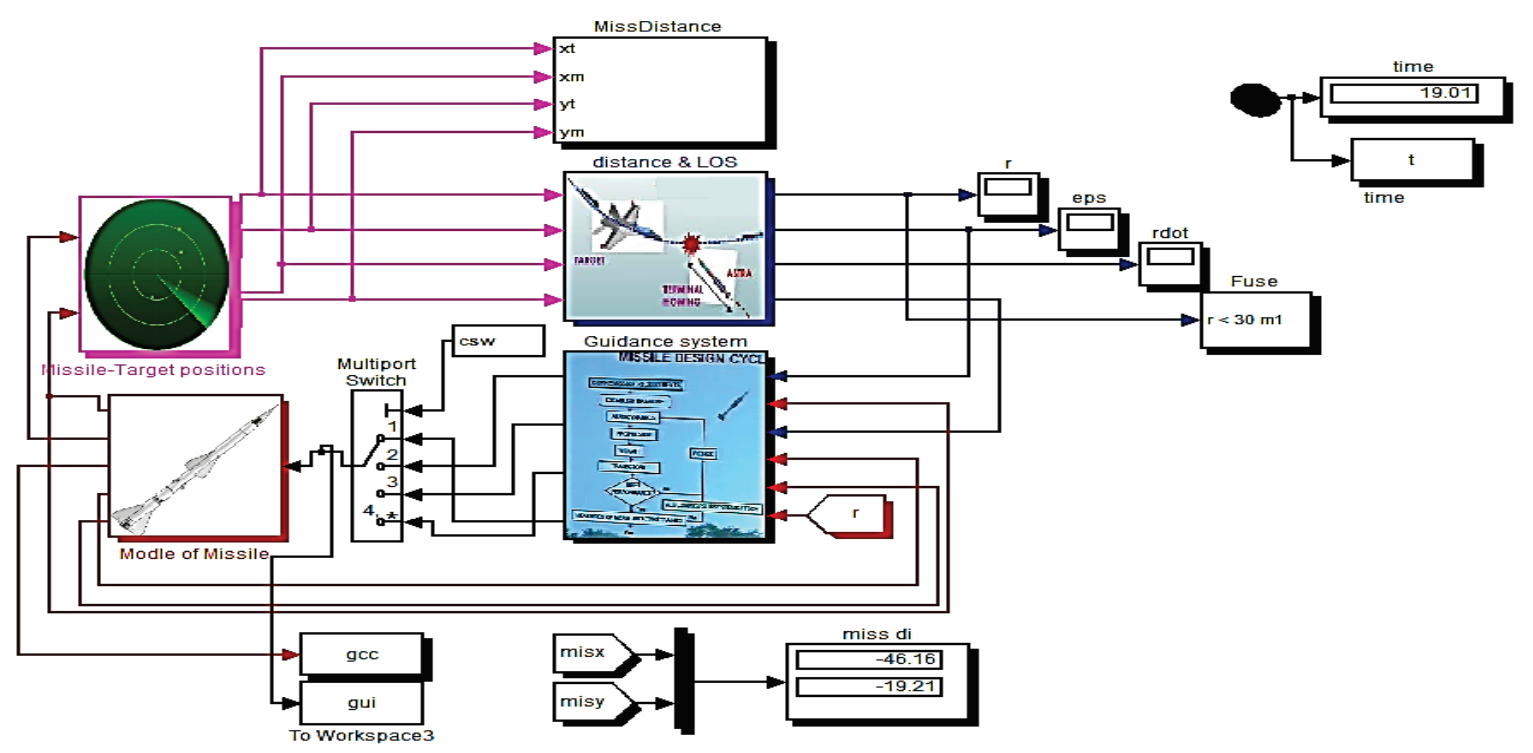

Figure 3 Overall simulation models of MGCSMC systems

\section{Results and Discussion}

To confirm the effectiveness of the proposed MGCSMC algorithm, the application of G\&C to the highaltitude flight angle of a SAM was simulated. In this simulation, the missile successfully reached the destruction area of the target for all cases of the manoeuvring target. The proposed MGCSMC method had high accuracy of destruction although it took some time for the method to achieve $100 \%$ accuracy for the highaltitude target, as shown in Fig. 4.

The simulation is performed through two scenarios. The first scenario compared the proposed MGCSMC method with the traditional PN method for missile guidance. The MGCSMC method achieved $100 \%$ accuracy in hitting the target, while the PN achieved $60 \%$ accuracy; failure occurred in three out of five simulation runs, as shown in Fig. 5. The success of the proposed method is attributed to the type of new command $\left(u_{1}\right.$, $u_{2}$ ) generations. These commands are proportionate to the error rate angle between the missile and sliding line $\dot{e}_{2}$, in addition, the simulation results indicate less chatter about the line-of-sight in MGCSMC than in the PN method, which therefore enables the missile to reach the target without losing more energy. For this reason, the missile does not need to generate a high value of command to track the target; it only needs to generate the appropriate command to ensure that the missile will be close to the sliding line or line-of-sight. The small value of command reduces the high oscillation of the missile around the lineof-sight, while the acceleration of missile was still around the line-of-sight (or sliding line) with minimum values to satisfy the sliding line criteria.

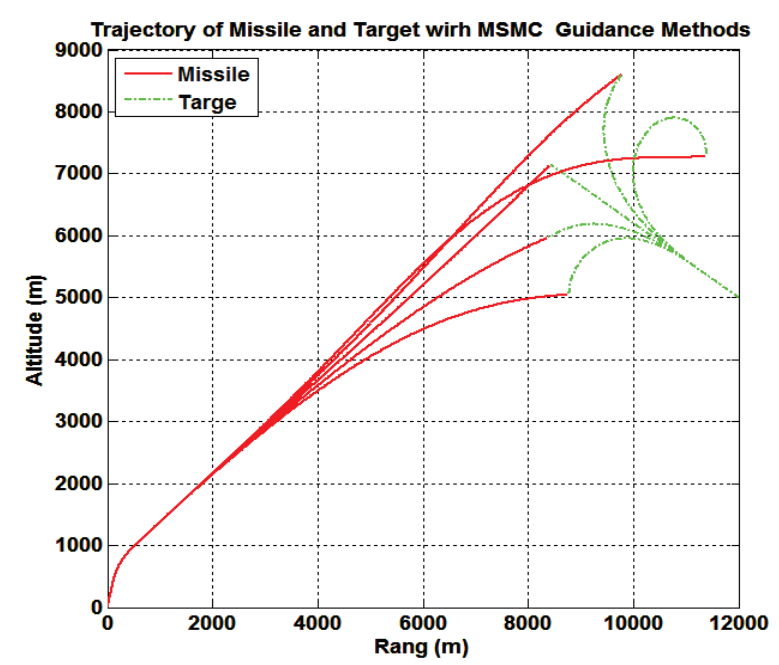

Figure 4 Trajectories of missile and manoeuvring target using the MGCSMC method

The proposed MGCSMC method kept the pitch angle rate close to zero and brought the missile in close 
proximity to the line-of-sight. Tab. 3 shows the summary results of scenario 1 .

Table 3 Summary results of the first scenario (low-altitude target)

\begin{tabular}{|l|c|c|c|}
\hline \multicolumn{1}{|c|}{ Method } & $t_{f}$ (finite time) / s & $\begin{array}{c}\text { Miss-distance } x / \\
\mathrm{m}\end{array}$ & $\begin{array}{c}\text { Miss-distance } y / \\
\mathrm{m}\end{array}$ \\
\hline PN & 20,78 & 46,4 & 18,6 \\
\hline MGCSMC & 16,79 & 20,1 & 12,2 \\
\hline
\end{tabular}

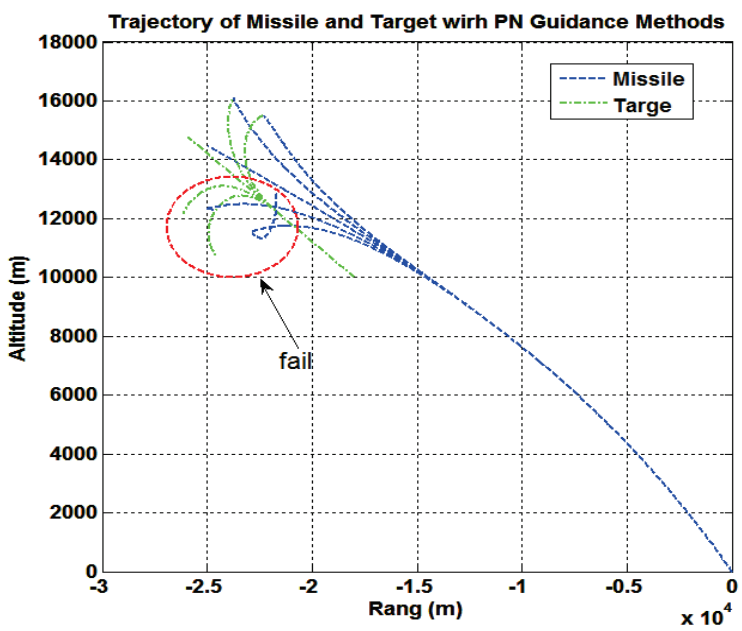

Figure 5 Trajectories of missile and manoeuvring target using the PN method

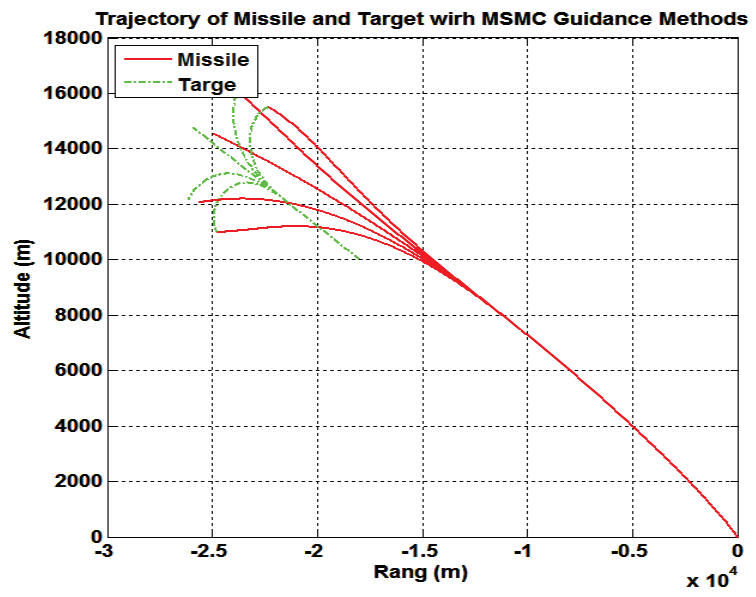

Figure 6 Trajectories of missile and target maneuvering on a highaltitude using the MGCSMC method

In the second scenario, (high-altitude target) can be seen by using the proposed MGCSMC method. This algorithm indicates the guidance system requirement for the engagement of the target with minimum miss distance and for an extended period of time. Whilst the PN method did not meet the requirement, and the missile failed to reach the target, as shown in Fig. 6 and Fig 7. A collision between the target and the missile was unnecessary because the approximate fuse will explode the missile within a certain default distance (20 meters for scenario 1 and 50 meters for scenario 2). Tab. 4 summarizes the results of the simulation of the second scenario.

Table 4 Summary results of the second scenario (high-altitude target)

\begin{tabular}{|l|c|c|c|}
\hline \multicolumn{1}{|c|}{ Method } & $t_{f}$ (finite time) / s & $\begin{array}{c}\text { Miss distance } x / \\
\mathrm{m}\end{array}$ & $\begin{array}{c}\text { Miss distance } y / \\
\mathrm{m}\end{array}$ \\
\hline PN & 42,0 & 36,7 & 34,0 \\
\hline MGCSMC & 32,0 & 20,7 & 25,0 \\
\hline
\end{tabular}

The results indicate that the MGCSMC meets all guidance requirements with high accuracy $100 \%$ accuracy of only $40 \%$ accuracy of the PN method.

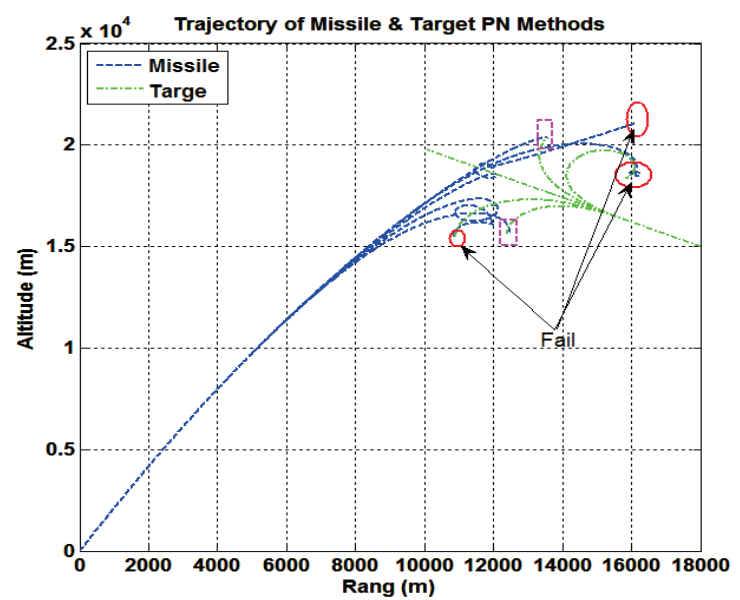

Figure 7 Trajectories of missile and target maneuvering on a highaltitude using PN method

\section{Conclusion}

A guidance and control system for missiles that must guide themselves autonomously to their air, surface or sea targets is of great importance. However, the guidance and control computations necessary for these missiles are extremely complicated which consist of hybrid components and require extensive processing power used to improve the performance of these missiles and depend on a variety of algorithms. These various algorithms have their advantages and disadvantages, challenges and complications. For example, a tactical air-to-air missile in pursuit of a highly maneuverable target aircraft is one of the most challenging of all guidance and control issues.

This paper proposes a novel algorithm that is integrated with each sub-algorithm, where it is selected as the suitable command signal depending on either the error value of the flight path of the missile to the LOS or its rate.

The advantage of the proposed MGCSMC algorithm is primarily significant in interception scenarios of highly manoeuvrable targets. The minimum effort of miss distance, obtained from combined state feedback with sliding mode of the interception problem. This proposal requires the selection of time-dependent controller gain, needed to ensure convergence of the missile response to the sliding surface in the presence of model uncertainties and target manoeuvres. The simulations show that small miss distance can be achieved even in stringent interception scenarios.

In addition to that, the proposed method performs well in guiding the missile to the impact point (target), even in situations of engagement with high-altitude target. Controlled instability due to modified sliding controller can be noticed in the simulation results consequently, the magnitude of control signal that is smaller than that of the conventional controller. In practice, if the controller induces smaller control signal with the same control performance, the controller used less energy. Therefore, smaller control input enhances energy efficiency. The proposed MGCSMC can eliminate the chattering which 
had been the main defects due to using conventional controller, and has better performance. This implementation assumes that the controlled system is smooth (chatter free). When the simulation grid-based system is not smooth, the simulation results are expected to be worse than the actual results. However, the pitch angle and the pitch angle rate track follow their command signals.

\section{References}

[1] Hongryel, K.; Jubum, S.; Jangmyung, L. A High-Speed Sliding-Mode Observer for the Sensorless Speed Control of a PMSM. // Industrial Electronics, IEEE Transactions on. 58, (2011), pp. 4069-4077.

[2] Lin, D.-f.; Fan, J.-f. Design and Numerical Simulation Analysis of Missile Control System. // in Computer Modeling and Simulation, ICCMS'10, Second International Conference on. (2010), pp. 142-145.

[3] Ming, X.; Balakrishnan, S. N.; Ohlmeyer, E. J. Integrated Guidance and Control of Missiles with Method. // Control Systems Technology, IEEE Transactions on. 14, (2006), pp. 981-992.

[4] Fan, J.; Qi, Z.; Lin, D. On Control for Static Unstable Missiles. // in Control Conference, CCC 2007. Chinese. (2007), pp. 464-468.

[5] Benshabat, D. G.; Bar-Gill, A. Robust command-to-line-ofsight guidance via variable-structure control. // Control Systems Technology, IEEE Transactions on. 3, (1995), pp. 356-361.

[6] Shah, M. Z.; Samar, R.; Bhatti, A. I. Adaptive sliding mode roll control of a canard-controlled missile. // in Control and Decision Conference (CCDC 2010), Chinese. (2010), pp. 2808-2813

[7] Kim, J.-J.; Lyou, J. Absolute Stability Margins in Missile Guidance Loop. // International Journal of Control, Automation, and Systems. 6, 4(2008), pp. 460-466.

[8] Chien-Chung, K.; Ciann-Dong, Y.; Keng-Lon, L. Control surface inverse algorithm and application to nonlinear $\mathrm{H}<$ sub $>$ \&infin; $</$ sub $>$ missile control. // in Decision and Control, Proceedings $42^{\text {nd }}$ IEEE Conference on. 5, (2003), pp. 5456-5461.

[9] Gong, Z. Q.; Zhu, G. Q. FDTD analysis of an anisotropically coated missile. // Progress in Electromagnetics Research. 64, (2006), pp. 69-80.

[10] Vinoth, M. S.; Saradhi, P.; Aditya, P. Intelligent guided missile. // in Intelligent Agent \& Multi-Agent Systems, IAMA 2009. International Conference on. (2009), pp. 1-4.

[11] Chang-Kyung, Ryoo; Yoon-Hwan, Kim; Min-Jea, Tahk; Keeyoung, Choi. A Missile Guidance Law Based on Sontag's Formula to Intercept Maneuvering Targets. // International Journal of Control, Automation, and Systems. 5, 4(2007), pp. 397-409.

[12] Guo, X.-W.; Kong, Z.-H.; Wang, Z.-L. Research on the Method of Simulation Modeling on the Control System of Certain Missile. // in Instrumentation, Measurement, Computer, Communication and Control, First International Conference on. (2011), pp. 909-912.

[13] Elmali, H.; Olgac, N. Robust output tracking control of nonlinear MIMO systems via sliding mode technique. // Automatica. 28, (1992), pp. 145-151.

[14] Yang, Z.-F.; Lei, H.-m.; Xu，X.-z.; Wu, P.; Li, Q.-1. Dynamic inverse control of nonlinear missile based on LSSVM. // in Intelligent Control and Automation (WCICA 2010) $8^{\text {th }}$ World Congress on. (2010), pp. 3367-3371.

[15] Zhang, X.; Zhu, X.; Yang, J. Design of Variable Structure Stability Control Loop for Anti-air Missile with Swing Nozzle Thrust Vector Control. // in Measuring Technology and Mechatronics Automation (ICMTMA 2011), Third International Conference on. (2011), pp. 1014-1017.

[16] Fallaha, C. J.; Saad, M.; Kanaan, H. Y.; Al-Haddad, K. Sliding-Mode Robot Control with Exponential Reaching Law. // Industrial Electronics, IEEE Transactions on. 58, (2011), pp. 600-610

[17] Dunnigan, M. W.; Wade, S.; Williams, B. W.; Yu, X. Position control of a vector controlled induction machine using Slotine's sliding mode control approach. // Electric Power Applications, IEE Proceedings. 145, (19989, pp. 231-238

[18] Hull, R. A.; Zhihua, Q. Dynamic robust recursive control design and its application to a nonlinear missile autopilot," in American Control Conference, Proceedings of the 1997. 1, (1997), pp. 833-837.

[19] Eker, İ.; Akınal, Ş. A. Sliding mode control with integral augmented sliding surface: design and experimental application to an electromechanical system. // Electrical Engineering. 90, (2008), pp. 189-197.

[20] Bag, S.; Spurgeon, S. K.; Edwards, C. Output feedback sliding mode design for linear uncertain systems. // IEEE Proceedings Control Theory and Applications. 144, (1997), pp. 209-216.

[21] Slotine, J.-J. E. Sliding controller design for non-linear systems. // International Journal of Control. 40, (1984), pp. 421-434

[22] Utkin, V.; Hoon, L. Chattering Problem in Sliding Mode Control Systems. // International Workshop on Variable Structure Systems, VSS'06. (2006), pp. 346-350.

\section{Authors' addresses}

\section{Dr. Ali Amer Ahmed Alrawi, Senior Lecturer}

School of Computer and Communication Engineering d/a School of Manufacturing Engineering Complex Universiti Malaysia Perlis (UniMAP)

1st Floor, Pauh Putra Main Campus, 02600 Arau, Perlis, Malaysia Mobile No. 010-5601429

E-mail: aliamer@unimap.edu.my

Dr. Stevica Graovac, Associate Professor

University of Belgrade,

School of Electrical Engineering

Bulevar kralja Aleksandra 73

11000 Belgrade, Serbia

E-mail: graovac@etf.rs

\section{Dr. R. Badlishah Ahmad, Professor}

School of Computer and Communication Engineering d/a School of Manufacturing Engineering Complex Universiti Malaysia Perlis (UniMAP)

1st Floor, Pauh Putra Main Campus, 02600 Arau, Perlis, Malaysia E-mail: badli@unimap.edu.my

\section{Dr. Md. Mijanur Rahman, Senior Lecturer}

School of Computer and Communication Engineering d/a School of Manufacturing Engineering Complex Universiti Malaysia Perlis (UniMAP)

1st Floor, Pauh Putra Main Campus, 02600 Arau, Perlis, Malaysia E-mail: mijanur@unimap.edu.my 


\section{Nomenclature}

$\alpha, \beta_{t}, \beta_{m}-$ angle of attack and sideslip angle

$\psi, \vartheta,-$ yaw and pitch angle

$\psi_{v}, \gamma_{M}-$ missile heading and flight-path angle

$\delta_{r}, \delta_{q}-$ deflection angles for yaw and pitch control

$\varepsilon_{m}, \varepsilon_{t}-$ error angles

$\theta_{m}, \theta_{t}, \varphi_{m}, \varphi_{t}-$ azimuth and elevation angles

$\sigma_{1,2}-$ sliding equation

$a_{x}-$ acceleration along $x$-axis

$a_{1}, a_{2}, b_{1,2}-$ system coefficients

$r, q-$ angular yaw and pitch rate

$u_{1}, u_{2}-$ commend signal from actuator

$g$ - gravity acceleration

$V_{m}-$ missile velocity

$V_{t}-$ target velocity

$r_{t}-$ target distance from the base station

$r_{m}-$ missile distance from base station

$J$ - moment of inertia

$T$ - thrust of missile

$D-$ drag

$m$ - mass of missile

$e_{1,2}-$ error

$x_{t}, y_{t}-$ target coordinates in the inertial reference frame

$x_{m}, y_{m}-$ missile coordinates in the inertial reference frame

$c_{2}$ - slope coefficient of sliding line equation

$L_{p}-$ Lyapunov's function

$k_{1,2}-$ state feedback gain

$x_{1,2}$ - states of the system

$u_{e q}$ - equivalent controller

$M$ - gain of sliding mode controller

VSC - Variable Structure Control

SMC - Sliding Mode Controller

MSMC - Modified Sliding Mode Controller

MGSCMC - Modify Sliding Mode Controller for

Guidance and Control Centre of Mass

$\mathrm{CG}$ - Centre of Gravity

$\mathrm{PN}$ - Proportional Navigation

G\&C - Guidance and Control

SAM - Surface to Air missile

$s\left(\theta_{m}\right)-\sin \left(\theta_{m}\right)$

$\mathrm{c}\left(\theta_{m}\right)-\cos \left(\theta_{m}\right)$ 